\title{
Electrochemotherapy of tumors as in situ vaccination boosted by immunogene electrotransfer
}

\author{
Gregor Sersa $^{1} \cdot$ Justin Teissie $^{2,3} \cdot$ Maja Cemazar $^{1,4} \cdot$ Emanuela Signori $^{5}$. \\ Urska Kamensek $^{1} \cdot$ Guillermo Marshall $^{6} \cdot$ Damijan Miklavcic $^{7}$
}

Received: 26 January 2015 / Accepted: 26 May 2015 / Published online: 12 June 2015

(C) The Author(s) 2015. This article is published with open access at Springerlink.com

\begin{abstract}
Electroporation is a platform technology for drug and gene delivery. When applied to cell in vitro or tissues in vivo, it leads to an increase in membrane permeability for molecules which otherwise cannot enter the cell (e.g., siRNA, plasmid DNA, and some chemotherapeutic drugs). The therapeutic effectiveness of delivered chemotherapeutics or nucleic acids depends greatly on their successful and efficient delivery to the target tissue. Therefore, the understanding of different principles of drug and gene
\end{abstract}

This paper is a Focussed Research Review based on a presentation given at the Fourteenth International Conference on Progress in Vaccination against Cancer (PIVAC 14), held in Rome, Italy, 24th-26th September, 2014. It is part of a Cancer Immunology, Immunotherapy series of Focussed Research Reviews and meeting report.

Gregor Sersa

gsersa@onko-i.si

1 Department of Experimental Oncology, Institute of Oncology Ljubljana, Zaloska 2, 1000 Ljubljana, Slovenia

2 IPBS (Institut de Pharmacologie et de Biologie Structurale), CNRS, 205 route de Narbonne BP64182, 31077 Toulouse, France

3 UPS, IPBS, Université de Toulouse, 31077 Toulouse, France

4 Faculty of Health Sciences, University of Primorska, Polje 42, 6310 Izola, Slovenia

5 Laboratory of Molecular Pathology and Experimental Oncology, CNR-Institute of Translational Pharmacology, Via Fosso del Cavaliere 100, 00133 Rome, Italy

6 Laboratorio de Sistemas Complejos, Departamento de Computación e Instituto de Física del Plasma, CONICET, Facultad de Ciencias Exactas y Naturales, Universidad de Buenos Aires, C1428EGA Buenos Aires, Argentina

7 Faculty of Electrical Engineering, University of Ljubljana, Trzaska 25, 1000 Ljubljana, Slovenia delivery is necessary and needs to be taken into account according to the specificity of their delivery to tumors and/ or normal tissues. Based on the current knowledge, electrochemotherapy (a combination of drug and electric pulses) is used for tumor treatment and has shown great potential. Its local effectiveness is up to $80 \%$ of local tumor control, however, without noticeable effect on metastases. In an attempt to increase systemic antitumor effectiveness of electrochemotherapy, electrotransfer of genes with immunomodulatory effect (immunogene electrotransfer) could be used as adjuvant treatment. Since electrochemotherapy can induce immunogenic cell death, adjuvant immunogene electrotransfer to peritumoral tissue could lead to locoregional effect as well as the abscopal effect on distant untreated metastases. Therefore, we propose a combination of electrochemotherapy with peritumoral IL-12 electrotransfer, as a proof of principle, using electrochemotherapy boosted with immunogene electrotransfer as in situ vaccination for successful tumor treatment.

Keywords Electroporation - Electrochemotherapy · Gene electrotransfer · Vaccination · Abscopal effect · PIVAC 14

$\begin{array}{ll}\text { Abbreviations } \\ \text { ATP } & \text { Adenosine triphosphate } \\ \text { B7-1 } & \text { B7 protein } \\ \text { CTL } & \text { Cytotoxic T cells } \\ \text { DAMP } & \text { Danger-associated molecular pattern molecules } \\ \text { DC } & \text { Dendritic cells } \\ \text { E } & \text { Electric field } \\ \text { GM-CSF } & \text { Granulocyte-macrophage colony-stimulating } \\ & \text { factor } \\ \text { GTP } & \text { Guanosine triphosphate } \\ \text { hTERT } & \text { Human telomerase reverse transcriptase } \\ \text { IL-12 } & \text { Interleukin 12 }\end{array}$




$\begin{array}{ll}\text { IL-2 } & \text { Interleukin } 2 \\ \text { PDGF- } \alpha & \text { Platelet-derived growth factor } \\ \text { pDNA } & \text { Plasmid DNA } \\ \text { ROS } & \text { Reactive oxygen species } \\ \text { siRNA } & \text { Small interfering RNA } \\ \text { TAA } & \text { Tumor-associated antigens } \\ \text { TLS } & \text { Tertiary lymphoid structures } \\ \text { TNF- } \alpha & \text { Tumor necrosis factor alpha } \\ \text { Treg } & \text { T regulatory cells } \\ U_{\mathrm{c}} & \text { Critical voltage } \\ U_{\mathrm{m}} & \text { Transmembrane voltage } \\ \text { VEGF } & \text { Vascular endothelial growth factor }\end{array}$

\section{Background}

It is known that malignant tumors are able to grow and spread because of their ability to escape the immune system surveillance. In fact, there is a process called "cancer immunoediting" that recognizes the existence of a fine interaction between the immune system and tumors, indicating the dual role the immunity plays in cancer [1]. Namely, the immune system not only protects the host against tumor growth, but can promote cancer development by selection of tumor variants with reduced immunogenicity [2]. One promising approach to treat cancer is so-called active immunotherapy, aiming to induce an endogenous tumor-specific immune response in the host. Immunotherapy strategies can include cancer vaccines based on plasmid DNA (pDNA) vectors used to deliver tumor antigens and/or immunomodulatory molecules to stimulate the immune system or oligonucleotides acting on immunosuppressor genes. Current data also support the idea that it is possible to strengthen the anticancer immune response by eliminating or inhibiting the immunosuppressive regulatory $\mathrm{T}$ cells (Treg) and by blocking the immune checkpoints [3-5].

In the treatment of tumors, several local therapeutic options are available, from surgery and radiotherapy as prevalent, to thermal ablation techniques, like radiofrequency ablation and cryosurgery, to electrochemotherapy, which is currently being recognized throughout Europe. The effectiveness and safety have brought electrochemotherapy into guidelines for the treatment of different cutaneous and subcutaneous tumors [6]. Recent meta-analysis has evaluated the effectiveness of several ablative skindirected therapies and clearly indicated the same, or even superior, effectiveness of electrochemotherapy over photodynamic therapy, radiotherapy, intralesional therapy, and topical therapy [7]. Many of these local treatments, like thermal ablation techniques, have different modes of tumor cell death that can elicit different local immune response, which is not sufficient to elicit also strong systemic effect.
However, these local treatments could be combined with immune adjuvants that would stimulate a more robust antitumor action and hopefully elicit also a systemic immune response [8]. For some of these local treatments, the elicited immune response resulted in a systemic effect, in socalled abscopal response on distant, nontreated nodules. Such cases were described after radiotherapy [9]. In light of these effects, novel approaches may, when appropriately designed, take advantage of the elicited local immune response and transform it into the systemic response. Electrochemotherapy, a combination of chemotherapy and electroporation, offers itself as another candidate.

In addition to electrochemotherapy, another biomedical application that is based on electroporation is gene electrotransfer, which even though still in early clinical developments has already entered several clinical trials [10]. In the clinical trial with plasmid coding for interleukin 12 (IL-12) electro transferred to some melanoma nodules, the local as well as the loco regional effect on nontreated nodules was observed [11]. Thus, gene electrotransfer of various immunomodulatory molecules could be used for the immunomodulation of the host's response. In this respect, local ablative effect of electrochemotherapy may set the stage for the enhanced systemic immune response that is elicited by delivery of the therapeutic gene into the organism with immunomodulatory activity.

When using electroporation as a platform technology for drug and gene delivery, electrical parameters must be adjusted for delivery of different molecules and for different target tissues [12, 13]. Electrical parameters that need to be considered are of temporal and spatial nature. Electric pulses that are delivered are of certain duration, shape and amplitude, which characterize their temporal nature. Electric pulses are delivered to cells/tissue via electrodes which, by their shape and positioning, together with the tissue anatomical features and electrical passive properties determine spatial distribution of current density and electric field, and this is to be considered of spatial nature. The community that intends to use this technology needs to be aware of the principles of electroporation effects at the cellular and tissue level based on temporal and spatial consideration, with respect to the specific molecules to be introduced.

Based on the assumption that local treatments can elicit immune response, which can be boosted by gene electrotransfer of immunomodulatory molecules, we need to develop strategies to combine local tumor treatments, such as electrochemotherapy with gene electrotransfer that will be tailored to specific tumor, tissue, and specific mode of action of the therapeutic molecule. In line with this, we describe here, principles of electroporation on cellular and tissue levels. We also propose a strategy, where electrochemotherapy-treated tumor could be used as a live vaccine in conjunction with gene electrotransfer to tumors 
(intratumorally or peritumorally) boosting local immune response to tumor together with "abscopal effect" on distant metastases.

\section{Cell electroporation can be controlled}

The knowledge of the theoretical background of electroporation is crucial to obtain the most suitable protocol for drug and/or gene delivery [14]. Two key phenomena are induced in the cell membrane: (1) the induced transmembrane voltage, which is crucial for achieving increased membrane permeability, and (2) the transport of the molecules through the permeabilized cell membrane during and after the electric pulse application.

When a cell is exposed to an external electric field $E$, a transmembrane voltage $U_{\mathrm{m}}$ is induced across the plasma membrane due to the difference between the electric properties of cell membrane, the cytoplasm, and external medium. The induced transmembrane voltage on a spherical cell for a constant electric pulse can be derived from the Laplace equation, which gives a time-dependent solution for the induced transmembrane voltage on a cell membrane [15]. After a membrane capacitance charging time $\left(t>10^{-7}\right.$ to $\left.10^{-6} \mathrm{~s}\right), U_{\mathrm{m}}$ can be described as:

$U_{\mathrm{m}}=f g(\lambda) r E \cos \theta$

in which $\theta$ designates the angle between the direction of the normal to the membrane at the considered point on the cell surface and the field direction, $E$ the field intensity, $r$ the radius of the cell, $g(\lambda)$ a function of the specific conductivities of the membrane $\left(\lambda_{\mathrm{m}}\right)$, the pulsing buffer $\left(\lambda_{\mathrm{o}}\right)$ and the cytoplasm $\left(\lambda_{i}\right)$, the membrane thickness and the cell size and $f$, which is a shape factor (a cell being a spheroid). $U_{\mathrm{m}}$ is not uniform on the cell surface. These physical predictions were checked experimentally by using potential difference-sensitive fluorescent probes [16, 17]. A key conclusion is that the induced transmembrane voltage depends on the cell size.

When the induced transmembrane voltage exceeds a certain value $U_{\mathrm{c}}$ (between 0.2 and $1 \mathrm{~V}$ ), which depends on the pulse parameters — number and duration [18] — the part of the cell membrane where $\left|U_{\mathrm{m}}\right|>U_{\mathrm{c}}$ is permeabilized-i.e., electrically conductive defects are formed in the membrane enabling the transport of molecules through the membrane [19].

The molecular reorganization of the membrane associated with this strong increase in transport is not fully understood, but a long-lived alteration of the membrane solution interface was observed [20]. Morphological changes of pulsed cells are present as a long-lived swelling is detected [21] associated with a global change in the membrane rheological properties [22]. No dramatic changes in the membrane organization are present in the long term [23].
However, significant but transient cytoplasmic disorganization occurs. Microtubules and microfilaments are disorganized, while intermediate filaments remain intact [24, 25]. Indeed, these alterations of the cytoskeleton are transient and under strong dependence on the composition of the pulsing buffer. The recovery of the cytoskeleton is associated with the short life of the permeabilized state of the membrane that recovers its selective permeability within a few minutes at physiological temperature [26]. This resealing process is not just due to the viscoelasticity of the membrane, but occurs through defect patching mediated by exocytotic pathways [27].

The membrane structural alterations induced by the electric pulses support transmembrane transport by diffusion of low molecular weight hydrophilic molecules. Membrane permeabilization due to electric pulses is nonselective and molecular flow occurs in both directions. The introduction of drugs like bleomycin or cisplatin is facilitated with consequent increase in their efficiency [12]. An important consequence of increased membrane permeability is also the outflow of secondary metabolites, like adenosine and guanosine triphosphate (ATP, GTP), which affects cell behavior [28, 29]. This may explain in part the observed effects on the cytoskeleton polymerization, which is controlled by these small molecules. Leakage of the ATP is also a danger signal and associated with immunogenic cell death, thus recruiting immune cells. Furthermore, the exposure of cells to electric pulses leads to the formation of reactive oxygen species (ROS) [30], which remain present during the increased membrane permeability.

Electrophoretic contribution during the pulse remains negligible in the long-term loading process [31]. Molecular transfer of small molecules $(<4 \mathrm{kDa})$ across the permeabilized area of the membrane is mostly driven by the concentration gradient across the membrane described by the Fick equation during the resealing process, i.e., after the pulse delivery [32] (Fig. 1).

On the contrary, transmembrane translocation of small interfering RNA (siRNA) occurs through the plasma membrane of cells during the electric pulse application [33, 34], which implies that siRNA does not penetrate the cells by diffusion as just described for small molecules. The amount of uploaded siRNA is therefore under the control of the cumulative pulse duration time and the electric field strength (Fig. 1).

In the case of plasmids (pDNA), these macromolecules interact with the plasma membrane by forming long-lived localized aggregates on the electropermeabilized area of the cell membrane [35]. This pDNA/membrane interaction occurs on the side where they are dragged by the electric field-mediated electrophoresis (Fig. 1). Along successive pulses, pDNAs accumulate in a restricted number of aggregates [36] and are translocated across the membrane. 


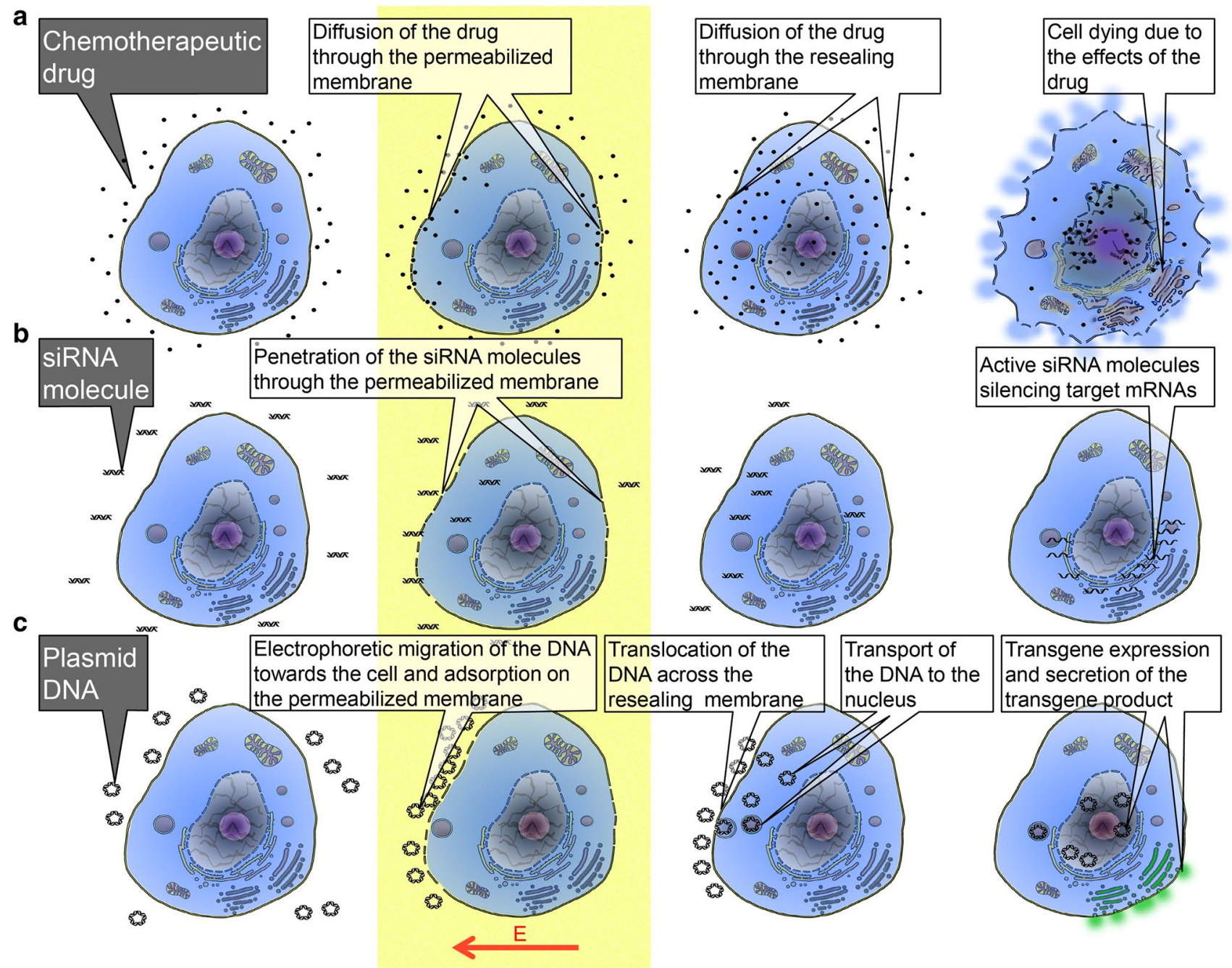

Fig. 1 Schematic cartoon showing the processes occurring before, during, and after application of electric pulses (yellow stripe) for the delivery of molecules of different sizes into the cell. a Delivery of small molecules - an example of electrochemotherapy; $\mathbf{b}$ delivery of

Transport within the cytoplasm is another step that happens several minutes after the pulse train. This is an active process under the control of the cytoplasmic ATP level. pDNA can be present in the cytoplasm in a free form that is transported to the nuclear envelope by molecular motors along the microtubules [37] or can be trapped within endocytoticlike actin-covered vesicles [38, 39]. During the residence time of pDNA in the membrane, associated aggregates are affected by the previously mentioned ROS generation. ROS generation can be prevented by adding antioxidants [40]. In summary, the electric pulses induce electrically mediated membrane reorganization, which is a localized event on the cell surface, and occur only when the local field strength is larger than a certain threshold value. Molecules can then cross the membrane giving them access to the cell cytoplasm. Molecular transport through the membrane can thus oligonucleotides - an example of siRNA electrotransfer; c delivery of larger nucleic acids/macromolecules-an example of pDNA gene electrotransfer

be controlled by pulse parameters such as amplitude, duration, shape, and number of pulses.

The processes occurring before, during, and after application of electric pulses are schematically presented in the Fig. 1. The delivery of small molecules is shown on an example of electrochemotherapy (Fig. 1a): Before the application of the pulses, the drug is dispersed around the cell; during the pulse and along the resealing of the permeabilized cell membrane, the drug molecules diffuse through the membrane with increased permeability; after the application of the pulses and the membrane resealing, the drug stays trapped in the cell where it can exert its cytotoxic effect. The delivery of oligonucleotides is shown on an example of siRNA electrotransfer (Fig. 1b): Before the application of the pulses, the siRNA molecules are dispersed around the cell; during the pulse delivery, the siRNA molecules translocate 


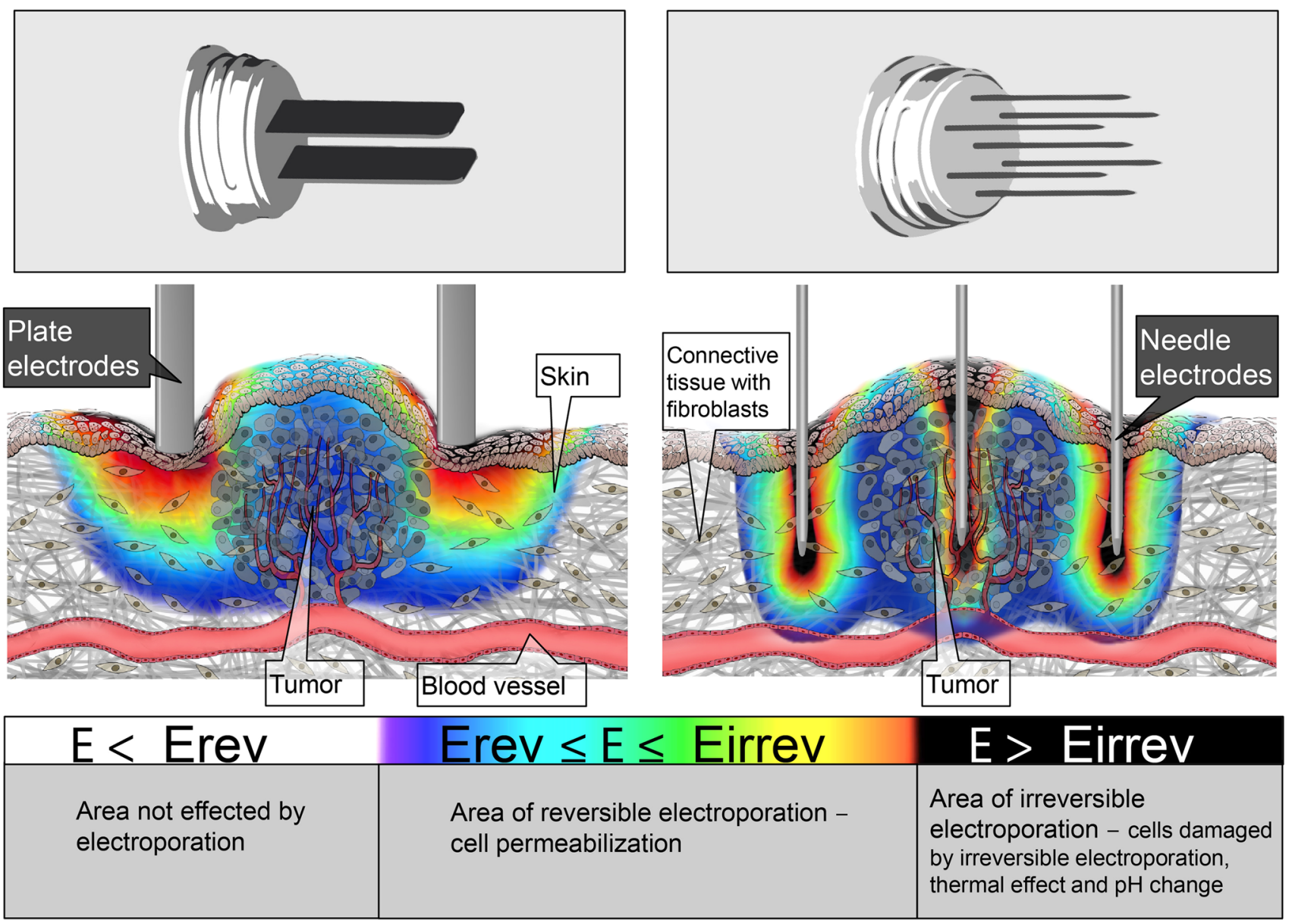

Fig. 2 Electric field distribution in and around the tumor tissue during the application of electric pulses for plate (left) and hexagonal needle electrodes - cross section through the mid-plane of the electrodes (right). The electric field distribution is indicated with the rainbow color scale

through the permeabilized membrane by electrophoresis; after the application of the pulses, the membrane reseals and uploaded siRNA molecules can silence the target mRNAs. The delivery of larger nucleic acids, i.e., macromolecules is shown on an example of pDNA electrotransfer (Fig. 1c): Before the application of the pulses, the pDNA is dispersed around the cell; during the delivery of the pulses, pDNA is dragged by the electric field-associated electrophoresis to the membrane where it adsorbs to the permeabilized part of the membrane and forms localized aggregates; during the resealing of the membrane, the pDNA is translocated across the membrane and transported to the nuclear envelope either by cytoskeletal transport or within endocytotic-like vesicles; once inside the nucleus, the gene encoded by the pDNA is transcribed, and then, therapeutic protein is translated on the ribosomes and, in the case of a gene encoding a secretory protein (for instance IL-12), the product is secreted by the cell; in the case of genes coding for tumor-associated antigens (TAA), proteins will be expressed in their cellular compartments (cell membrane or cytoplasm).

\section{Drug and gene delivery to cells in tissue depends on additional factors}

The behavior of cells when exposed to electric fields (pulses) cannot be translated directly from cells in vitro to tissues in vivo. Cells in tissue are embedded in a matrix, they are of several types in a certain organ (heterogeneous population), and they form electrical connections between themselves mediated by cell-to-cell junctions [41]. So the values of critical electric field at which cell membrane becomes permeabilized cannot be determined in vitro and then used in in vivo experiments. Furthermore, different tissue properties such as perfusion (better perfusion is usually associated with higher electric conductivity), cell density and cell volume fraction, preferential orientation like in muscle, all affect the electric conductivity of the tissue. Skin has a considerably lower conductivity than any other tissue; muscle conductivity along muscle fibers is higher than in perpendicular direction and tumor tissues generally have higher conductivity than tissue in which they 
are embedded-even in the liver, which is highly conductive tissue [42]. As a consequence, when we deliver electric pulses using electrodes (either penetrating needles type or nonpenetrating, e.g., surface plate electrodes or pins), the electric current distributes according to the electrode and tissue geometry and tissue conductivity; current and electric field are dual and are connected in place and time through Ohm's law (Fig. 2). In principle at the same current, higher conductivity will result in lower electric field and vice versa. This means that if electric pulses are applied across the skin, the highest electric field will be in the skin [43]. As electroporation of cell membrane is a consequence of induced transmembrane voltage on the cell membrane [15], cells in high electric field will get permeabilized first. Once they are permeabilized, the conductivity changes and electric field distribution changes as well [44].

It has been shown before that geometry of electrodes and tissue electric properties (i.e., conductivity) determines the electric field which in turn results in increased cell membrane permeability [45]. This means that we can, by choosing different electrodes and controlling their placement with respect to target tissue, achieve controlled membrane permeabilization of target tissues [42, 46]. This is true and well used in treating deep-seated tumors by means of electrochemotherapy [47], but is also true that when using different electrodes in the same in vivo "assay," different results are achieved [48] as will be discussed later.

Taking into account the nonhomogeneous nature of tissue [43] and that permeabilization of the cell membrane also depends on the duration and number of the applied pulses [18], at the current state of knowledge, it is important to determine experimentally, which is the threshold and necessary electric field to be achieved in target tissue. This was determined to be $400 \mathrm{~V} / \mathrm{cm}$ for 8 short (100 $\mu \mathrm{s})$ duration electric pulses, delivered at $1 \mathrm{~Hz}$ pulse repetition frequency for the delivery of small molecules to tumors in vivo [49]. The course of tissue permeabilization was studied on a mathematical model of a subcutaneous tumor in small animals [49] and seems also to correspond well in humans based on clinical observations [50]. For rabbit liver using the same parameters, threshold was determined to be $460 \mathrm{~V} / \mathrm{cm}[51,52]$. For rat muscle, the threshold was different depending on whether the pulses were delivered in parallel or perpendicular to the muscle fiber orientation and was 80 and $200 \mathrm{~V} / \mathrm{cm}$, respectively [53].

Electric field distribution in and around the tumor tissue during the application of electric pulses for the plate and hexagonal needle electrodes is shown in the Fig. 2. If the electric field is under the threshold for reversible electroporation, the cells are not affected by electroporation (Fig. 2, white areas); if the electric field is above the threshold for reversible and under the threshold for irreversible electroporation, the cells can reseal and survive after electroporation (Fig. 2, blue to red areas); and if the electric field exceeds the threshold for irreversible electroporation, the cells are destroyed/damaged by the effects of irreversible electroporation, thermal effect, and $\mathrm{pH}$ changes (Fig. 2, black areas).

For gene electrotransfer in vivo it was shown that membrane permeabilization, which is achieved by high voltage, i.e., permeabilizing pulse(s), is a critical step [54]. But perhaps even more critical is using sufficiently long (from 1 to several $100 \mathrm{~ms}$ ) low voltage electric pulse or a combination of low voltage electric pulses that are applied after membrane permeabilization, to achieve effective uptake of pDNA into the target cells in tissue [55, 56]. Several different combinations of high voltage, short duration and low voltage, long duration electric pulses were tested and determined empirically for successful gene electrotransfer into different tissues, muscle, skin, tumor, and liver (for specific electrical parameters see [57]). However, several other electrical parameters employing only one type of pulses could also be used for effective gene electrotransfer to tumors muscle and skin [58-61]. Longer pulses, however, were mostly reported to be needed for successful gene transfer.

As the electric field in the tissue depends on tissue properties and anatomy (i.e., geometry), it is important to define target tissue, which is relatively easy in case of tumors and electrochemotherapy, but less in the case of gene electrotransfer aiming at achieving immune response [62]. Depending on the type of therapeutic gene, i.e., tumor antigen or co-stimulatory immune molecules and the target tissues (skin-only dermis or also subcutaneous tissue, muscle, etc.), the target cells in specific tissue are different. Furthermore, it was also shown that target cells are not necessarily present where and when the pulses are applied for the first time [63]. For instance, exposure of skeletal muscle to electric pulses alone causes influx of inflammatory cells that can uptake the pDNA injected several days after the application of electric pulses [63], thus resulting in strong and fast immune response. Furthermore, we need to be aware that for gene electrotransfer, it is mandatory to achieve reversible permeabilization in cells that need to be transfected and avoid irreversible electroporation of these same cells, since they should not be damaged as they need to express the transgene. Finally, we need to be aware that even it might seem rather controversial at the first glance, short membrane permeabilizing, i.e., short, high voltage electric pulses may be less detrimental to the tissue than electrophoretic, i.e., long, low voltage pulses, as they result in higher temperature increase [64], but also in large changes of $\mathrm{pH}$, even extreme changes [65]. However, these are mostly restricted to the immediate vicinity of the electrodes.

Another important aspect that needs to be taken into account when evaluating the gene electrotransfer protocols 
is the usage of plasmids encoding reporter genes. The results from the studies using reporter genes cannot be directly transferred to the therapeutic application of gene electrotransfer. Different efficiency was achieved by the same electrodes and treatment parameters considering gene expression of reporter gene Luciferase in cells in situ (the ones that were exposed to electric pulses) or at induced immune response of plasmid encoding modified form of human telomerase reverse transcriptase gene (hTERT) measured by $h T E R T$-specific cytotoxic T cells (CTL) isolated from spleens 14 days after gene electrotransfer to skin [48].

\section{Electrochemotherapy elicits immune response}

Electroporation represents a platform technology for delivery of different molecules to cells and tissues. From its preclinical development, it has quickly been transferred into the treatment of tumors in human and veterinary oncology [13]. Electroporation leads to a transient increase in the permeability of cell membranes when exposed to electric pulses [13]. By use of this technology, specific chemotherapeutic molecules like bleomycin and cisplatin have enhanced uptake in the cells, thus leading to their better cytotoxic effectiveness. This therapeutic approach, electrochemotherapy, has 50-80\% complete response rate of the treated tumors [67], but has only a local effect without systemic effect on distant metastases.

Electrochemotherapy induces apoptotic and necrotic cell death in tumors, and extensive necrotic areas in the tumors are observed after a few days [68]. This leads to tumor antigen shedding in the tumor surrounding. Several lines of evidence support this notion. Recently, properties of immunogenic cell death after electrochemotherapy were demonstrated in a murine tumor model [66].

Firstly, some of the preclinical studies demonstrated infiltration of immune cells into the tumors, indicating an inflammatory reaction [69]. This reaction is due also to the liberation of the cell metabolites that are shed from cells that underwent necrotic cell death, and elicits adaptive immune response [66]. Besides preclinical studies [51], also electrochemotherapy of human melanoma induced maturation of dendritic cells (DC) and their subsequent migration into draining lymph nodes [70]. Furthermore, the release of ATP after electroporation of cells serves also as attractant for DC and their precursors and favors their maturation into antigen presenting cells [66].

Secondly, for complete regression of the tumors after electrochemotherapy, we need to eradicate (kill) all the tumor-initiating (stem) cells. However, due to the technical limits, as well as tissue properties, we cannot effectively cover whole tumor with the sufficient electric field to permeabilize all cells within the tumor, or the drug is not available for the cells' uptake. Thus, we have to presume that the immune response is responsible for the eradication of all the remaining tumor cells, which is supported by the results of the study where we demonstrated that after electrochemotherapy complete responses of the tumors were obtained in immunocompetent mice, whereas in $\mathrm{T}$ cell-deficient nude mice not $[51,71,72]$. Such observations are common also after radiotherapy [73]. Another line of evidence comes from the studies where adjuvant treatment using different cytokines, like IL- 2 and TNF- $\alpha$, were combined with electrochemotherapy resulting in increased antitumor effectiveness [69, 71, 74].

Thirdly, one of the first studies of electrochemotherapy in immunocompetent mice has indicated on the induction of the systemic immune response after electrochemotherapy of tumors. Monocytes isolated from venous blood of electrochemotherapy-treated mice showed increased ability to elicit oxidative burst by production of toxic oxygen species 7 days after treatment. Besides activation of monocytes, which are involved in nonspecific tumor destruction and activation of other components of the immune system, also adaptive immune arm was activated, demonstrated by activation of T lymphocytes. However, this activation may not be sufficient for abscopal effect on distant metastases [75]. On the other hand, none of the in vitro and in vivo studies in mice or clinical studies have demonstrated that electrochemotherapy promotes metastatic process in the organism [75-77]. However, it was shown that electrochemotherapy can induce immunogenic cell death demonstrated by exposure of calreticulin, liberation of ATP, and the release of high mobility group box 1 protein from CT26 colon carcinoma cells in vitro. Such electrochemotherapytreated cells, when injected into syngeneic mice also protected the animals against tumor challenge demonstrating vaccination effect [66]. Hence, electrochemotherapy may represent an interesting approach to treat solid tumors while preventing recurrence and metastases.

Fourthly, the effect of electrochemotherapy depends also on the immunogenicity of the treated tumors; more immunogenic tumors respond better and with a higher cure rate $[78,79]$. In line with these observations, we can also speculate that although electroporation is an effective technology for drug delivery, based mainly on physico-electrical properties, the response rate of the tumors at least to some degree depends also on the tumor type, having in mind also intrinsic sensitivity (resistance) to the chemotherapeutic drug $[69,79,80]$. Some lines of evidence for that exist also for human studies since slight variations in tumor responsiveness were observed in meta-analysis performed on clinical studies on electrochemotherapy published so far [67]. Furthermore, a clinical study on electrochemotherapy of melanoma in patients has demonstrated tumor-infiltrating 


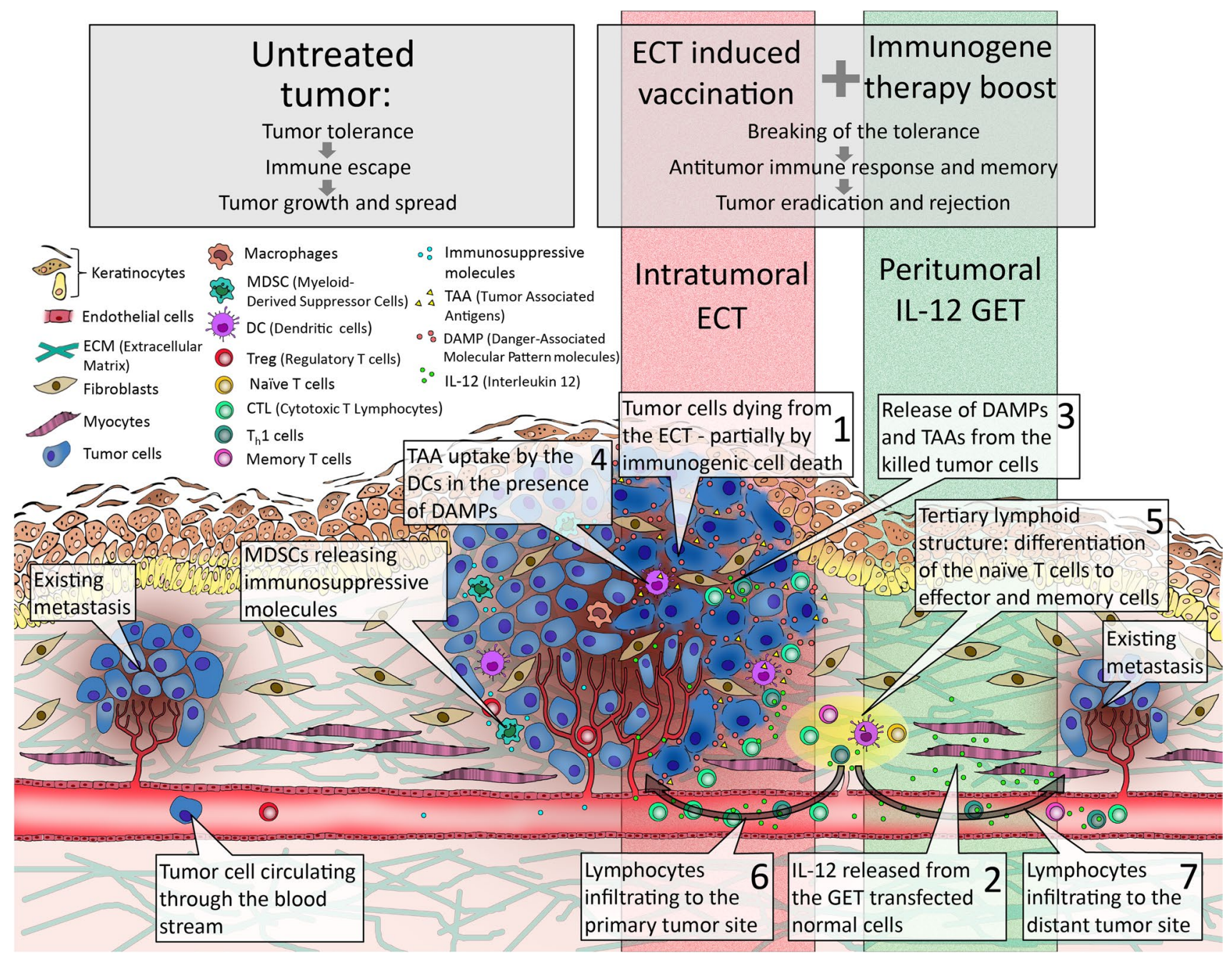

Fig. 3 Proposed model for electrochemotherapy of tumors as in situ vaccination boosted by immunogene electrotransfer. ECT electrochemotherapy, GET gene electrotransfer

lymphocytes following treatment, but there was no correlation between their number or distribution and the local response or visceral spread, whereas FoxP3 as a master control gene of Treg was upregulated in tumors that had faster dissemination into the visceral organs [91].

\section{Electrotransfer of immunomodulatory genes adds a systemic component to electrochemotherapy}

Gene electrotransfer is another electroporation-based application, where pDNA or siRNA molecules can be delivered to various tissues, including tumors [81, 82].

Gene electrotransfer is considered to be an effective tool in eliciting antigen-specific immune response in small and large animal models, being responsible for the generation of an inflammatory environment with immune cell infiltration [83]. The migration of these cells seems to be essential to initiate an adequate immune response to the DNA vaccine, proving that this technique is effective in the stimulation of humoral and cellular immunity [84].

Depending on the immunogenicity of the tumors and the immune status of the organism, in vivo gene electrotransfer of pDNAs coding for immunomodulatory molecules such as cytokines, chemokines, adjuvant sequences, siRNA, and/ or administration of DNA vaccines carrying tumor-specific or TAA can be used alone or in combination with chemotherapeutics for treatment of tumors [85]. Several therapeutic genes were examined, IL-12, VEGF, PDGF- $\alpha$, etc. [8688], but no detailed study of the immune response locally or systemically was conducted. All these studies report that gene electrotransfer is effective in activating the antitumor effectiveness. The therapeutic gene can be administered either intratumorally or peritumorally for predominantly local effectiveness, or into the muscle to induce systemic shedding of the therapeutic molecule. Some studies using 
IL-2 or IL-12 demonstrated also the antitumor effectiveness on distant untreated tumors and long-term memory of the immune system to tumor cells $[69,89,90]$. As a single treatment, the intratumoral administration of cytokine gene electrotransfer seems the most appropriate way to obtain good therapeutic effect. One of the most studied cytokines is IL-12, with several preclinical studies in different tumor types demonstrating its effectiveness [87], which was proved also in clinical treatment of melanoma patients [86]. Daud et al. [11] have demonstrated that treatment of a few melanoma nodules in the patient can elicit, in certain patients, slow, but an efficient immune response of the organism that results in regression of the treated and also nontreated nodules, as well as prolonged survival without progression of the disease.

Some studies have also explored the combination of local therapies with the gene electrotransfer of immunomodulatory genes. The combinations with either radiotherapy or electrochemotherapy were explored. The strategy was similar, radiosensitization or chemosensitization by immunoadjuvant therapy that boosted the immune response of the organism against tumor [77, 91-96]. A good potentiation of the radiation response and electrochemotherapy was noted, but the underlying immunomodulatory mechanisms were not explored. The knowledge of the mechanisms underlying the elicited immune response by local therapy, such as electrochemotherapy, would lead into the proper scheduling of suitable combination therapies for elicitation of systemic immune response. Thus, appropriate dosage of the pDNA encoding immunomodulatory molecules and the scheduling of it need to be determined [97]. Additionally, suitable biomarkers that would predict the treatment response are needed. Currently, it seems that several consecutive immunogene therapies are necessary. Indeed, in preclinical studies, it was shown that at least three consecutive immunogene electrotransfers should be performed, one prior to electrochemotherapy and two consecutive ones thereafter [78]. Skin gene electrotransfer is very appealing, since the skin is a tissue with vast amounts of immune cells capable of eliciting an efficient vaccination and boosting effect. Some studies have already shown that DC activation in the treatment of melanoma may be an exciting approach [98] (Fig. 3).

The immune response linked to electrochemotherapy and immunomodulatory gene electrotransfer remains to be fully investigated taking into account also the inhibitory function of Tregs, which have been implicated as one of the major suppressive mechanisms of antitumor immune responses. In the tumor environment, Treginduced immune suppression poses a significant barrier to anticancer responses targeted by immunotherapeutic strategies. Whelan et al. [4] have demonstrated that an increase or decrease in Tregs has a direct influence on the effect of an immunotherapy approach administered by gene electrotransfer of plasmid vectors encoding GM-CSF and B7-1, coupled with the systemic administration of Treg inactivation molecules such as anti-CD25 antibody. More recently, the new results indicate the potential for combining Treg depletion with immunotherapy-based gene electrotransfer into the B16F10 melanoma tumor model to decrease systemic metastasis and potentially enhance survival [99].

Current data also support the idea that it is possible to induce elimination or inhibition of immunosuppressive Treg cells through chemotherapy [100]. Thus, such approach should be especially focused on the possibility to strengthen anticancer immune reactivity. New targeted chemotherapy should therefore be used, preferably for the induction of immunogenic cancer cell death [3].

Here, we propose a model, a combination of electrochemotherapy with immunostimulating peritumoral IL-12 electrotransfer, as a proof of principle that electrochemotherapy can be used as in situ vaccination boosted with immunogene electrotransfer (Fig. 3). In the untreated tumor (Fig. 3, left), immunosuppressive microenvironment with suppressive immune cells like Tregs and myeloid-derived suppressor cells (MDSC) leads to tumor tolerance, and tumor cells escape the immune system and can replicate uncontrollably and spread through the body to form distant secondary tumors. The electrochemotherapy-induced vaccination boosted with IL-12 immunogene therapy (Fig. 3, right) leads to the breaking of the tolerance to otherwise weekly immunogenic intrinsic tumor antigens that result in an antitumor immune response and memory responsible for regression of the treated tumor and untreated distant metastases. Namely, electrochemotherapy-induced tumor cell deaths (Fig. 3, speech balloon 1) combined with IL-12 released into the bloodstream from the transfected cells in the peritumoral region (Fig. 3, speech balloon 2) create a pro-inflammatory microenvironment that leads to recruitment of circulating immune cells. Tumor cells die, at least in part, by immunogenic form of cell death characterized by the shedding of TAA and danger-associated molecular pattern molecules (DAMP) (Fig. 3, speech balloon 3) from the dying cells. Released TAA are captured by DC (Fig. 3, speech balloon 4) that migrate to local lymph node-like structures called tertiary lymphoid structures (TLS) [101] or to the draining lymph nodes (Fig. 3, speech balloon 5) where they initiate adaptive antitumor immune response by priming the naïve $\mathrm{T}$ cell to become effector and memory $\mathrm{T}$ cells. Tumor-specific lymphocytes, like cytotoxic $\mathrm{T}$ lymphocytes and Th1 cells, are then released from the lymphoid structures via circulation and can infiltrate the primary tumor site (Fig. 3, speech balloon 6) and distant 
metastases (Fig. 3, speech balloon 7) where they exert their immunological actions.

Furthermore, an exciting therapeutic approach to further provide a systemic effectiveness and to enhance the local antitumor response of electrochemotherapy could be the immune checkpoint blockade and/or inhibiting Tregs.

\section{Conclusion}

Membrane electroporation leading to increased membrane permeability is a phenomenon which allows the introduction of non- or poorly permeant molecules into the cells. The key factors governing electroporation are the amplitude of induced transmembrane voltage which depends on the electric field to which the cell is locally exposed, to the cell size, shape, and its orientation in the field. It is important to stress that the local electric field $E$ is the critical parameter for membrane electroporation/permeabilization as it defines the area of the membrane which is permeabilized and through which ionic and molecular transport occurs [102].

Similar to the effects at the molecular and cellular level, a considerable amount of knowledge has been accumulated about properties of tissues and how these affect cell electroporation in the tissue and consequently drug and gene electrotransfer. In spite of the fact that the exact mechanisms involved at the molecular level of the cells and tissue electroporation are not fully understood, it is possible to determine a set of electrical parameters, providing safe and efficient procedure for in vivo applications that could be translated into clinical use.

Electrochemotherapy is an efficient local ablative treatment, which is currently employed in numerous oncology centers throughout Europe. However, it is a local treatment, which would need a systemic component that would boost the immune response of electrochemotherapy itself. Therefore, gene electrotransfer of immunomodulatory molecules in the peritumoral skin could add this systemic component, by enhancing locoregional and/or systemic response. Hence, we propose a strategy, where electrochemotherapytreated tumor could be used as a live vaccine in conjunction with gene electrotransfer to tumors.

Acknowledgments The Slovenian Research Agency has supported this research by grants P3-0003, P2-0249. The Midi-Pyrénées Region has financially supported this work (Grant 11052700). Research was conducted in the scope of the EBAM European Associated Laboratory (LEA) and resulted from the networking efforts of the COST Action TD1104 (www.electroporation.net).

Conflict of interest All authors declare no conflict of interest, except Damijan Miklavcic, who holds patents on electrochemotherapy that have been licensed to IGEA S.p.a. He is also a consultant to IGEA.
Open Access This article is distributed under the terms of the Creative Commons Attribution 4.0 International License (http://creativecommons.org/licenses/by/4.0/), which permits unrestricted use, distribution, and reproduction in any medium, provided you give appropriate credit to the original author(s) and the source, provide a link to the Creative Commons license, and indicate if changes were made.

\section{References}

1. Dunn GP, Old LJ, Schreiber RD (2004) The immunobiology of cancer immunosurveillance and immunoediting. Immunity 21:137-148. doi:10.1016/j.immuni.2004.07.017

2. Zou WP (2005) Immunosuppressive networks in the tumour environment and their therapeutic relevance. Nat Rev Cancer 5:263-274. doi:10.1038/Nrc1586

3. Bruserud O, Ersvaer E, Olsnes A, Gjertsen BT (2008) Anticancer immunotherapy in combination with proapoptotic therapy. Curr Cancer Drug Targets 8:666-675. doi:10.2174/156800908786733496

4. Whelan MC, Casey G, MacConmara M, Lederer JA, Soden D, Collins JK, Tangney M, O'Sullivan GC (2010) Effective immunotherapy of weakly immunogenic solid tumours using a combined immunogene therapy and regulatory T-cell inactivation. Cancer Gene Ther 17:501-511. doi:10.1038/Cgt.2010.8

5. Pardoll DM (2012) The blockade of immune checkpoints in cancer immunotherapy. Nat Rev Cancer 12(4):252-264. doi: $10.1038 / \mathrm{nrc} 3239$

6. Miklavcic D, Mali B, Kos B, Heller R, Sersa G (2014) Electrochemotherapy: from the drawing board into medical practice. Biomed Eng Online. doi:10.1186/1475-925x-13-29

7. Spratt DE, Spratt EAG, Wu SH, DeRosa A, Lee NY, Lacouture ME, Barker CA (2014) Efficacy of skin-directed therapy for cutaneous metastases from advanced cancer: a meta-analysis. $\mathbf{J}$ Clin Oncol 32:3144-3155. doi:10.1200/Jco.2014.55.4634

8. Chu KF, Dupuy DE (2014) Thermal ablation of tumours: biological mechanisms and advances in therapy. Nat Rev Cancer 14:199-208. doi:10.1038/Nrc3672

9. Postow MA, Callahan MK, Barker CA et al (2012) Immunologic correlates of the abscopal effect in a patient with melanoma. N Engl J Med 366:925-931. doi:10.1056/NEJMoa1112824

10. Heller R, Heller LC (2014) Gene electrotransfer clinical trials. Adv Genet 89:235-262. doi:10.1016/bs.adgen.2014.10.006

11. Daud AI, DeConti RC, Andrews S et al (2008) Phase I trial of interleukin-12 plasmid electroporation in patients with metastatic melanoma. J Clin Oncol 26:5896-5903. doi:10.1200/ JCO.2007.15.6794

12. Mir LM, Orlowski S (1999) Mechanisms of electrochemotherapy. Adv Drug Deliv Rev 35:107-118. doi:10.1016/ S0169-409X(98)00066-0

13. Yarmush ML, Golberg A, Sersa G, Kotnik T, Miklavcic D (2014) Electroporation-based technologies for medicine: principles, applications, and challenges. Annu Rev Biomed Eng 16:295-320. doi:10.1146/annurev-bioeng-071813-104622

14. Teissie J, Golzio M, Rols MP (2005) Mechanisms of cell membrane electropermeabilization: a minireview of our present (lack of ?) knowledge. Biochim Biophys Acta 1724:270-280. doi:10.1016/j.bbagen.2005.05.006

15. Kotnik T, Kramar P, Pucihar G, Miklavcic D, Tarek M (2012) Cell membrane electroporation-part 1: the phenomenon. IEEE. 28:14-23. doi:10.1109/Mei.2012.6268438

16. Gross D, Loew LM, Webb WW (1986) Optical imaging of cellmembrane potential changes induced by applied electric-fields. Biophys J 50:339-348 
17. Hibino M, Shigemori M, Itoh H, Nagayama K, Kinosita K (1991) Membrane conductance of an electroporated cell analyzed by submicrosecond imaging of transmembrane potential. Biophys J 59:209-220. doi:10.1016/S0006-3495(91)82212-3

18. Pucihar G, Krmelj J, Rebersek M, Napotnik TB, Miklavcic D (2011) Equivalent pulse parameters for electroporation. IEEE Trans Biomed Eng 58:3279-3288. doi:10.1109/TBME.2011.2167232

19. Kotnik T, Pucihar G, Miklavcic D (2010) Induced transmembrane voltage and its correlation with electroporation-mediated molecular transport. J Membr Biol 236(1):3-13. doi:10.1007/ s00232-010-9279-9

20. Lopez A, Rols MP, Teissie J (1988) P-31 NMR analysis of membrane phospholipid organization in viable, reversibly electropermeabilized chinese-hamster ovary cells. Biochemistry 27:1222-1228. doi:10.1021/Bi00404a023

21. Golzio M, Mora MP, Raynaud C, Delteil C, Teissie J, Rols MP (1998) Control by osmotic pressure of voltage-induced permeabilization and gene transfer in mammalian cells. Biophys $\mathbf{J}$ 74:3015-3022. doi:10.1016/S0006-3495(98)78009-9

22. Chopinet L, Roduit C, Rols MP, Dague E (2013) Destabilization induced by electropermeabilization analyzed by atomic force microscopy. BBA-Biomembranes 1828:2223-2229. doi:10.1016/j.bbamem.2013.05.035

23. Escoffre JM, Bellard E, Faurie C, Sebai SC, Golzio M, Teissie J, Rols MP (2014) Membrane disorder and phospholipid scrambling in electropermeabilized and viable cells. BBA-Biomembranes 1838:1701-1709. doi:10.1016/j.bbamem.2014.02.013

24. Kanthou C, Kranjc S, Sersa G, Tozer G, Zupanic A, Cemazar $M$ (2006) The endothelial cytoskeleton as a target of electroporation-based therapies. Mol Cancer Ther 5:3145-3152. doi:10.1158/1535-7163.MCT-06-0410

25. Meulenberg CJ, Todorovic V, Cemazar M (2012) Differential cellular effects of electroporation and electrochemotherapy in monolayers of human microvascular endothelial cells. PLoS One 7:e52713. doi:10.1371/journal.pone.0052713

26. Lindner P, Neumann E, Rosenheck K (1977) Kinetics of permeability changes induced by electric impulses in chromaffin granules. J Membr Biol 32:231-254

27. Huynh C, Roth D, Ward DM, Kaplan J, Andrews NW (2004) Defective lysosomal exocytosis and plasma membrane repair in Chediak-Higashi/beige cells. Proc Natl Acad Sci USA 101:16795-16800. doi:10.1073/pnas.0405905101

28. Volker TT, Pianet I, Labouesse J, Teissie J (1989) Signal transduction by membrane receptors in viable electropermeabilized cells: isoproterenol-stimulated cyclic AMP synthesis in C6 glioma cells. Biochim Biophys Acta 984:243-251. doi:10.1016/0005-2736(89)90223-X

29. Sersa G, Miklavcic D, Cemazar M, Rudolf Z, Pucihar G, Snoj M (2008) Electrochemotherapy in treatment of tumours. Eur J Surg Oncol 34:232-240. doi:10.1016/j.ejso.2007.05.016

30. Gabriel B, Teissie J (1994) Generation of reactive-oxygen species induced by electropermeabilization of Chinese hamster ovary cells and their consequence on cell viability. Eur J Biochem 223:25-33. doi:10.1111/j.1432-1033.1994.tb18962.x

31. Pucihar G, Kotnik T, Miklavcic D, Teissie J (2008) Kinetics of transmembrane transport of small molecules into electropermeabilized cells. Biophys J 95:2837-2848. doi:10.1529/ biophysj.108.135541

32. Rols MP, Teissie J (1990) Electropermeabilization of mammalian-cells-quantitative-analysis of the phenomenon. Biophys $\mathbf{J}$ 58:1089-1098. doi:10.1016/S0006-3495(90)82451-6

33. Paganin-Gioanni A, Bellard E, Escoffre JM, Rols MP, Teissie J, Golzio M (2011) Direct visualization at the single-cell level of siRNA electrotransfer into cancer cells. Proc Natl Acad Sci USA 108:10443-10447. doi:10.1073/pnas.1103519108
34. Breton M, Delemotte L, Silve A, Mir LM, Tarek M (2012) Transport of siRNA through lipid membranes driven by nanosecond electric pulses: an experimental and computational study. J Am Chem Soc 134:13938-13941. doi:10.1021/ Ja3052365

35. Golzio M, Teissie J, Rols MP (2002) Direct visualization at the single-cell level of electrically mediated gene delivery. Proc Natl Acad Sci USA 99:1292-1297. doi:10.1073/pnas.022646499

36. Escoffre JM, Portet T, Favard C, Teissie J, Dean DS, Rols MP (2011) Electromediated formation of DNA complexes with cell membranes and its consequences for gene delivery. BBA-Biomembranes 1808:1538-1543. doi:10.1016/j.bbamem.2010.10.009

37. Vaughan EE, Dean DA (2006) Intracellular trafficking of plasmids during transfection is mediated by microtubules. Mol Ther 13:422-428. doi:10.1016/j.ymthe.2005.10.004

38. Rosazza C, Escoffre JM, Zumbusch A, Rols MP (2011) The actin cytoskeleton has an active role in the electrotransfer of plasmid DNA in mammalian cells. Mol Ther 19:913-921. doi:10.1038/Mt.2010.303

39. Markelc B, Skvarca E, Dolinsek T, Kloboves VP, Coer A, Sersa G, Cemazar M (2015) Inhibitor of endocytosis impairs gene electrotransfer to mouse muscle in vivo. Bioelectrochemistry 103:111-119. doi:10.1016/j.bioelechem.2014.08.020

40. Markelc B, Tevz G, Cemazar M, Kranjc S, Lavrencak J, Zegura B, Teissie J, Sersa G (2012) Muscle gene electrotransfer is increased by the antioxidant tempol in mice. Gene Ther 19:312-320. doi:10.1038/Gt.2011.97

41. Chin RS, Stuchly MA (2005) Electric fields in bone marrow substructures at power-line frequencies. IEEE Trans Biomed Eng 52:1103-1109. doi:10.1109/Tbme.2005.846712

42. Miklavcic D, Corovic S, Pucihar G, Pavselj N (2006) Importance of tumour coverage by sufficiently high local electric field for effective electrochemotherapy. EJC Suppl 4:45-51. doi:10.1016/j.ejcsup.2006.08.006

43. Pavselj N, Miklavcic D (2008) Numerical modeling in electroporation-based biomedical applications. Radiol Oncol 42:159-168. doi:10.2478/v10019-008-0008-2

44. Corovic S, Lackovic I, Sustaric P, Sustar T, Rodic T, Miklavcic D (2013) Modeling of electric field distribution in tissues during electroporation. Biomed Eng Online 12:16. doi:10.1186/1475-925X-12-16

45. Miklavcic D, Beravs K, Semrov D, Cemazar M, Demsar F, Sersa G (1998) The importance of electric field distribution for effective in vivo electroporation of tissues. Biophys J 74:21522158. doi:10.1016/S0006-3495(98)77924-X

46. Miklavcic D, Snoj M, Zupanic A et al (2010) Towards treatment planning and treatment of deep-seated solid tumors by electrochemotherapy. Biomed Eng Online. doi:10.1186/1475-925x-9-10

47. Edhemovic I, Gadzijev EM, Brecelj E et al (2011) Electrochemotherapy: a new technological approach in treatment of metastases in the liver. Technol Cancer Res Treat 10:475-485

48. Calvet CY, Thalmensi J, Pliquet E, Liard C, Bestetti T, Demoyen PL, Huet T, Mir LM (2014) Optimization of intradermal gene electrotransfer procedure for human telomerasebased DNA vaccination. Mol Ther 22:S246-S. doi:10.1038/ $\mathrm{mtm} .2014 .45$

49. Pavselj N, Bregar Z, Cukjati D, Batiuskaite D, Mir LM, Miklavcic D (2005) The course of tissue permeabilization studied on a mathematical model of a subcutaneous tumor in small animals. IEEE Trans Biomed Eng 52:1373-1381. doi:10.1109/ TBME.2005.851524

50. Kos B, Zupanic A, Kotnik T, Snoj M, Sersa G, Miklavcic D (2010) Robustness of treatment planning for electrochemotherapy of deep-seated tumors. J Membr Biol 236:147-153. doi:10.1007/s00232-010-9274-1 
51. Miklavcic D, Semrov D, Mekid H, MirLM (2000) A validated model of in vivo electric field distribution in tissues for electrochemotherapy and for DNA electrotransfer for gene therapy. Biochim Biophys Acta 1523:73-83. doi:10.1016/S0304-4165(00)00101-X

52. Sel D, Cukjati D, Batiuskaite D, Slivnik T, Mir LM, Miklavcic D (2005) Sequential finite element model of tissue electropermeabilization. IEEE Trans Biomed Eng 52:816-827. doi:10.1109/TBME.2005.845212

53. Corovic S, Zupanic A, Kranjc S, Al Sakere B, Leroy-Willig A, Mir LM, Miklavcic D (2010) The influence of skeletal muscle anisotropy on electroporation: in vivo study and numerical modeling. Med Biol Eng Comput 48:637-648. doi:10.1007/ s11517-010-0614-1

54. Satkauskas S, Bureau MF, Puc M, Mahfoudi A, Scherman D, Miklavcic D, Mir LM (2002) Mechanisms of in vivo DNA electrotransfer: respective contributions of cell electropermeabilization and DNA electrophoresis. Mol Ther 5:133-140. doi:10.1006/mthe.2002.0526

55. Satkauskas S, Andre F, Bureau MF, Scherman D, Miklavcic D, Mir LM (2005) Electrophoretic component of electric pulses determines the efficacy of in vivo DNA electrotransfer. Hum Gene Ther 16:1194-1201. doi:10.1089/hum.2005.16.1194

56. Calvet CY, Andre FM, Mir LM (2014) Dual therapeutic benefit of electroporation-mediated DNA vaccination in vivo Enhanced gene transfer and adjuvant activity. Oncoimmunology 3:e28131. doi:10.4161/onci.28540

57. Andre FM, Gehl J, Sersa G et al (2008) Efficiency of highand low-voltage pulse combinations for gene electrotransfer in muscle, liver, tumor, and skin. Hum Gene Ther 19:1261-1271. doi:10.1089/Hum.2008.060

58. Cemazar M, Golzio M, Sersa G, Hojman P, Kranjc S, Mesojednik S, Rols MP, Teissie J (2009) Control by pulse parameters of DNA electrotransfer into solid tumors in mice. Gene Ther 16:635-644. doi:10.1038/gt.2009.10

59. Guo SQ, Donate A, Basu G, Lundberg C, Heller L, Heller R (2011) Electro-gene transfer to skin using a noninvasive multielectrode array. J Control Release 151:256-262. doi:10.1016/j. jconrel.2011.01.014

60. Ferraro B, Cruz YL, Coppola D, Heller R (2009) Intradermal delivery of plasmid $\operatorname{VEGF}(165)$ by electroporation promotes wound healing. Mol Ther 17:651-657. doi:10.1038/Mt.2009.12

61. Marie C, Vandermeulen G, Quiviger M, Richard M, Preat V, Scherman D (2010) pFARs, plasmids free of antibiotic resistance markers, display high-level transgene expression in muscle, skin and tumour cells. J Gene Med 12(4):323-332. doi:10.1002/jgm. 1441

62. Zupanic A, Kos B, Miklavcic D (2012) Treatment planning of electroporation-based medical interventions: electrochemotherapy, gene electrotransfer and irreversible electroporation. Phys Med Biol 57:5425-5440. doi:10.1088/0031-9155/57/17/5425

63. Peng B, Zhao Y, Xu L, Xu Y (2007) Electric pulses applied prior to intramuscular DNA vaccination greatly improve the vaccine immunogenicity. Vaccine 25:2064-2073. doi:10.1016/j. vaccine. 2006.11 .042

64. Lackovic I, Magjarevic R, Miklavcic D (2009) Three-dimensional finite-element analysis of joule heating in electrochemotherapy and in vivo gene electrotransfer. IEEE 16:1338-1347. doi:10.1109/TDEI.2009.5293947

65. Olaiz N, Signori E, Maglietti F, Soba A, Suarez C, Turjanski P, Michinski S, Marshall G (2014) Tissue damage modeling in gene electrotransfer: the role of $\mathrm{pH}$. Bioelectrochemistry 100:105-111. doi:10.1016/j.bioelechem.2014.05.001

66. Calvet CY, Famin D, Andre FM, Mir LM (2014) Electrochemotherapy with bleomycin induces hallmarks of immunogenic cell death in murine colon cancer cells. Oncoimmunology 3:e28131. doi:10.4161/onci.28131
67. Mali B, Jarm T, Snoj M, Sersa G, Miklavcic D (2013) Antitumor effectiveness of electrochemotherapy: a systematic review and meta-analysis. Eur J Surg Oncol 39:4-16. doi:10.1016/j. ejso.2012.08.016

68. Cemazar M, Miklavcic D, Scancar J, Dolzan V, Golouh R, Sersa G (1999) Increased platinum accumulation in SA-1 tumour cells after in vivo electrochemotherapy with cisplatin. Br J Cancer 79:1386-1391. doi:10.1038/sj.bjc.6690222

69. Mir LM, Roth C, Orlowski S, Quintin-Colonna F, Fradelizi D, Belehradek J Jr, Kourilsky P (1995) Systemic antitumor effects of electrochemotherapy combined with histoincompatible cells secreting interleukin-2. J Immunother Emphas Tumor Immunol 17:30-38

70. Gerlini G, Sestini S, Di Gennaro P, Urso C, Pimpinelli N, Borgognoni L (2013) Dendritic cells recruitment in melanoma metastasis treated by electrochemotherapy. Clin Exp Metastasis 30(1):37-45. doi:10.1007/s10585-012-9505-1

71. Sersa G, Cemazar M, Menart V, Gaberc-Porekar V, Miklavcic D (1997) Anti-tumor effectiveness of electrochemotherapy with bleomycin is increased by TNF-alpha on SA-1 tumors in mice. Cancer Lett 116:85-92. doi:10.1016/S0304-3835(97)00170-5

72. Sersa G, Miklavcic D, Cemazar M, Belehradek J, Jarm T, Mir LM (1997) Electrochemotherapy with CDDP on LPB sarcoma: comparison of the anti-tumor effectiveness in immunocompetent and immunodeficient mice. Bioelectrochem Bioenerg 43:279-283. doi:10.1016/S0302-4598(96)05194-X

73. Frey B, Rubner Y, Wunderlich R, Weiss EM, Pockley AG, Fietkau R, Gaipl US (2012) Induction of abscopal anti-tumor immunity and immunogenic tumor cell death by ionizing irradiation-implications for cancer therapies. Curr Med Chem 19:1751-1764. doi:10.2174/092986712800099811

74. Cemazar M, Todorovic V, Scancar J, Lampreht U, Stimac M, Kamensek U, Kranjc S, Coer A, Sersa G (2015) Adjuvant TNF- $\alpha$ therapy to electrochemotherapy with intravenous cisplatin in murine sarcoma exerts synergistic antitumor effectiveness. Radiol Oncol 49(1):32-40. doi:10.1515/raon-2015-0005

75. Sersa G, Kotnik V, Cemazar M, Miklavcic D, Kotnik A (1996) Electrochemotherapy with bleomycin in SA-1 tumor-bearing mice-natural resistance and immune responsiveness. Anticancer Drugs 7:785-791. doi:10.1097/00001813-199609000-00011

76. Todorovic V, Sersa G, Mlakar V, Glavac D, Flisar K, Cemazar M (2011) Metastatic potential of melanoma cells is not affected by electrochemotherapy. Melanoma Res 21:196-205. doi:10.1097/CMR.0b013e328337abd7

77. Ramirez LH, Orlowski S, An D et al (1998) Electrochemotherapy on liver tumours in rabbits. Br J Cancer 77:2104-2111

78. Sedlar A, Dolinsek T, Markelc B, Prosen L, Kranjc S, Bosnjak M, Blagus T, Cemazar M, Sersa G (2012) Potentiation of electrochemotherapy by intramuscular IL-12 gene electrotransfer in murine sarcoma and carcinoma with different immunogenicity. Radiol Oncol 46:302-311. doi:10.2478/v10019-012-0044-9

79. Sersa G, Cemazar M, Miklavcic D, Mir LM (1994) Electrochemotherapy-variable antitumor effect on different tumor-models. Bioelectrochem Bioenerg 35:23-27. doi:10.1016/0302-4598(94)87006-3

80. Cemazar M, Miklavcic D, Sersa G (1998) Intrinsic sensitivity of tumor cells to bleomycin as an indicator of tumor response to electrochemotherapy. Jpn J Cancer Res 89:328-333

81. Stevenson FK, Ottensmeier CH, Rice J (2010) DNA vaccines against cancer come of age. Curr Opin Immunol 22:264-270. doi:10.1016/j.coi.2010.01.019

82. Sioud M (2015) RNA interference: mechanisms, technical challenges, and therapeutic opportunities. Methods Mol Biol 1218:1-15. doi:10.1007/978-1-4939-1538-5_1

83. Scheerlinck JP, Karlis J, Tjelle TE, Presidente PJ, Mathiesen I, Newton SE (2004) In vivo electroporation improves immune 
responses to DNA vaccination in sheep. Vaccine 22:1820-1825. doi:10.1016/j.vaccine.2003.09.053

84. Chiarella P, Massi E, De Robertis M, Sibilio A, Parrella P, Fazio VM, Signori E (2008) Electroporation of skeletal muscle induces danger signal release and antigenpresenting cell recruitment independently of DNA vaccine administration. Expert Opin Biol Ther 8:1645-1657. doi: $10.1517 / 14712598.8 .11 .1645$

85. Cemazar M, Sersa G (2007) Electrotransfer of therapeutic molecules into tissues. Curr Opin Mol Ther 9:554-562

86. Heller LC, Heller R (2010) Electroporation gene therapy preclinical and clinical trials for melanoma. Curr Gene Ther 10:312-317. doi:10.2174/156652310791823489

87. Cemazar M, Jarm T, Sersa G (2010) Cancer electrogene therapy with interleukin-12. Curr Gene Ther 10:300-311

88. Glikin GC, Finocchiaro LM (2014) Clinical trials of immunogene therapy for spontaneous tumors in companion animals. Sci World J 2014:718520. doi:10.1155/2014/718520

89. Lucas ML, Heller R (2003) IL-12 gene therapy using an electrically mediated nonviral approach reduces metastatic growth of melanoma. DNA Cell Biol 22(12):755-763. doi:10.1089/104454903322624966

90. Pavlin D, Cemazar M, Kamensek U, Tozon N, Pogacnik A, Sersa G (2009) Local and systemic antitumor effect of intratumoral and peritumoral IL-12 electrogene therapy on murine sarcoma. Cancer Biol Ther 8(22):2114-2122. doi:10.2478/ v10019-010-0041-9

91. Sedlar A, Kranjc S, Dolinsek T, Cemazar M, Coer A, Sersa G (2013) Radiosensitizing effect of intratumoral interleukin-12 gene electrotransfer in murine sarcoma. BMC Cancer 13:38. doi:10.1186/1471-2407-13-38

92. Tevz G, Kranjc S, Cemazar M, Kamensek U, Coer A, Krzan M, Vidic S, Pavlin D, Sersa G (2009) Controlled systemic release of interleukin-12 after gene electrotransfer to muscle for cancer gene therapy alone or in combination with ionizing radiation in murine sarcomas. J Gene Med 11:1125-1137. doi:10.1002/ Jgm. 1403

93. Kamensek U, Sersa G, Cemazar M (2013) Evaluation of p21 promoter for interleukin 12 radiation induced transcriptional targeting in a mouse tumor model. Mol Cancer 12(1):136. doi:10.1186/1476-4598-12-136

94. Kishida T, Asada H, Itokawa Y, Yasutomi K, Shin-Ya M, Gojo S, Cui FD, Ueda Y, Yamagishi H, Imanishi J, Mazda O (2003)
Electrochemo-gene therapy of cancer: intratumoral delivery of interleukin-12 gene and bleomycin synergistically induced therapeutic immunity and suppressed subcutaneous and metastatic melanomas in mice. Mol Ther 8(5):738-745. doi:10.1016/j. ymthe.2003.08.002

95. Torrero MN, Henk WG, Li S (2006) Regression of highgrade malignancy in mice by bleomycin and interleukin-12 electrochemogenetherapy. Clin Cancer Res 12(1):257-263. doi:10.1158/1078-0432.CCR-05-1514

96. Heller L, Pottinger C, Jaroszeski MJ, Gilbert R, Heller R (2000) In vivo electroporation of plasmids encoding GM-CSF or interleukin-2 into existing B16 melanomas combined with electrochemotherapy induces long-term antitumour immunity. Melanoma Res 10(6):577-583

97. Shirley SA, Lundberg CG, Li F, Burcus N, Heller R (2015) Controlled gene delivery can enhance therapeutic outcome for cancer immune therapy for melanoma. Curr Gene Ther 15(1):32-43. doi:10.2174/1566523214666141121111630

98. Quaglino P, Osella-Abate S, Marenco F, Nardo T, Gado C, Novelli M, Savoia P, Bernengo MG (2011) FoxP3 expression on melanoma cells is related to early visceral spreading in melanoma patients treated by electrochemotherapy. Pigment Cell Melanoma Res. 24:734-736. doi:10.1111/j.1755-148X.2011.00879.x

99. Forde PF, Sadadcharam M, Hall LJ, O’Donovan TR, de Kruijf M, Byrne WL, O'Sullivan GC, Soden DM (2014) Enhancement of electroporation facilitated immunogene therapy via T-reg depletion. Cancer Gene Ther 21:349-354. doi:10.1038/ Cgt.2014.35

100. Zheng Y, Dou Y, Duan L, Cong C, Gao A, Lai Q, Sun Y (2015) Using chemo-drugs or irradiation to break immune tolerance and facilitate immunotherapy in solid cancer. Cell Immunol 294(1):54-59. doi:10.1016/j.cellimm.2015.02.003 Epub 2015 Feb 10

101. Goc J, Fridman WH, Sautes-Fridman C, Dieu-Nosjean MC (2013) Characteristics of tertiary lymphoid structures in primary cancers. Oncoimmunology 2:e26836. doi:10.4161/ onci.26836

102. Pucihar G, Kotnik T, Valic B, Miklavcic D (2006) Numerical determination of transmembrane voltage induced on irregularly shaped cells. Ann Biomed Eng 34:642-652. doi:10.1007/ s10439-005-9076-2 